\title{
Effect of machining parameters on deformation behaviour of Al-based metal-matrix-composites under tension
}

\author{
A. Pramanik ${ }^{1, *}$, A. K. Basak ${ }^{2}$ \\ ${ }^{1}$ Department of Mechanical Engineering, Curtin University, Bentley, WA, Australia \\ ${ }^{2}$ Adelaide Microscopy, The University of Adelaide, Adelaide, SA, Australia \\ *Corresponding author, Email: alokesh.pramanik@curtin.edu.au, Phone: + 61892667981
}

\begin{abstract}
The effect of machining parameters, such as reinforcement size, machining speed and feed rate on tensile strength, strain at break and fractured surfaces of Al-based metal matrix composites (MMCs) were analyses in this present investigation. It was found that larger particles induce higher stiffness on machined MMC parts machined at higher speed and lower feed, providing constant input parameters are of low values and vice versa. The effect of reinforcement size on tensile strength is negligible and higher speed and lower feed give higher tensile strength when constant input parameters are of low values. The higher machining speed gives higher strain at break though reinforcement size and feed rate have minor effect on strain at break when the constant input parameters are of high values. When the constant input parameters are of low values, the smaller reinforcement, machining speed and feed rate give higher strain at break. Ductile fracture occurs in all cases regardless of input variables and smaller nodules were formed on fractured surface in the case of smaller particles reinforced MMCs.
\end{abstract}

Key words: Cutting; surface; metal matrix composite; tension; deformation. 


\section{Introduction}

Incorporation of hard and brittle particles in ductile materials, such as aluminium alloys, induces effects, such as interactions between tool and particles, no-uniform plastic deformation, initiation of crack in the material etc., during machining of such materials which are commonly known as metal matrix composites [1-3]. These additional effects change machining mechanisms of MMCs. Nonuniform and severe plastic deformation contributes to compressive residual stress in freshly generated surface, segmented chips and enhanced disposability of chips $[4,5]$. Lower strength of the formed chips during machining and enhanced disposability probably form cracks in the shear zone which results in discontinuous chip formation. Severe wear in cutting tool and voids/cavities on freshly generated surface are contributed by interactions between tool and particles [6]. A number of studies have been conducted addressing the effect of machining parameters on surface integrity of the machined MMCs parts as well as the effect of 'surface defect minimization process' [7-11]. However, application of 'surface defect minimization processes' for parts used in practical applications are very expensive and not realistic from commercial point of view. In literature, enough information is not available on the behaviour of MMCs with imperfect surface integrity generated by different machining processes. Most of the parts used in the practical applications are processed by standard machining processes such as, turning, grinding, milling etc. These processes affect the integrity of freshly generated machined surface which ultimately dictate the performance of the parts in services [12]. So far there is no study on the effect of machining conditions on the deformation of MMCs reinforced with particles of different size under tension, though it is imperatively needed to improve the design of parts machined from MMCs. In view of that, the objective of the present study is to investigate the effect of reinforcement size, machining conditions and their interactions on tensile behaviour of MMCs. This will contribute towards better understanding on the performance of machined MMC components.

\section{Materials and methods}

The metal matrix composites were made of 6061 aluminum alloy reinforced with 10 vol. \% SiC particles through ex-situ method followed by hot-isotatic pressing. Two different particle sizes were explored: $13 \mu \mathrm{m}$ and $0.7 \mu \mathrm{m}$ (approximately). Fig. 1 shows the microstructure of the above mentioned MMCs after standard metallographic polishing [13] and reveal that the reinforcing particles are evenly distributed in the metal matrix. Test specimens had the dimensions according to ASTM standard[14] as shown in Fig. 2, schematically and fabricated by milling process at different 
machining conditions from a plate of $137 \times 42 \times 9 \mathrm{~mm}^{3}$ MMCs block. A total of 8 machined samples were tested in the EZ 50 tensile testing machine (Lloyd instruments, AMETEK) to investigate the influence of input parameters on the deformation of MMC under tension. The depth of cut for all specimens was constant at $0.25 \mathrm{~mm}$. The tensile force was applied to a longitudinal tension test specimen is in the direction of the greatest extension. The cross head speed was limited to a maximum value of $2 \mathrm{~mm} / \mathrm{min}$.
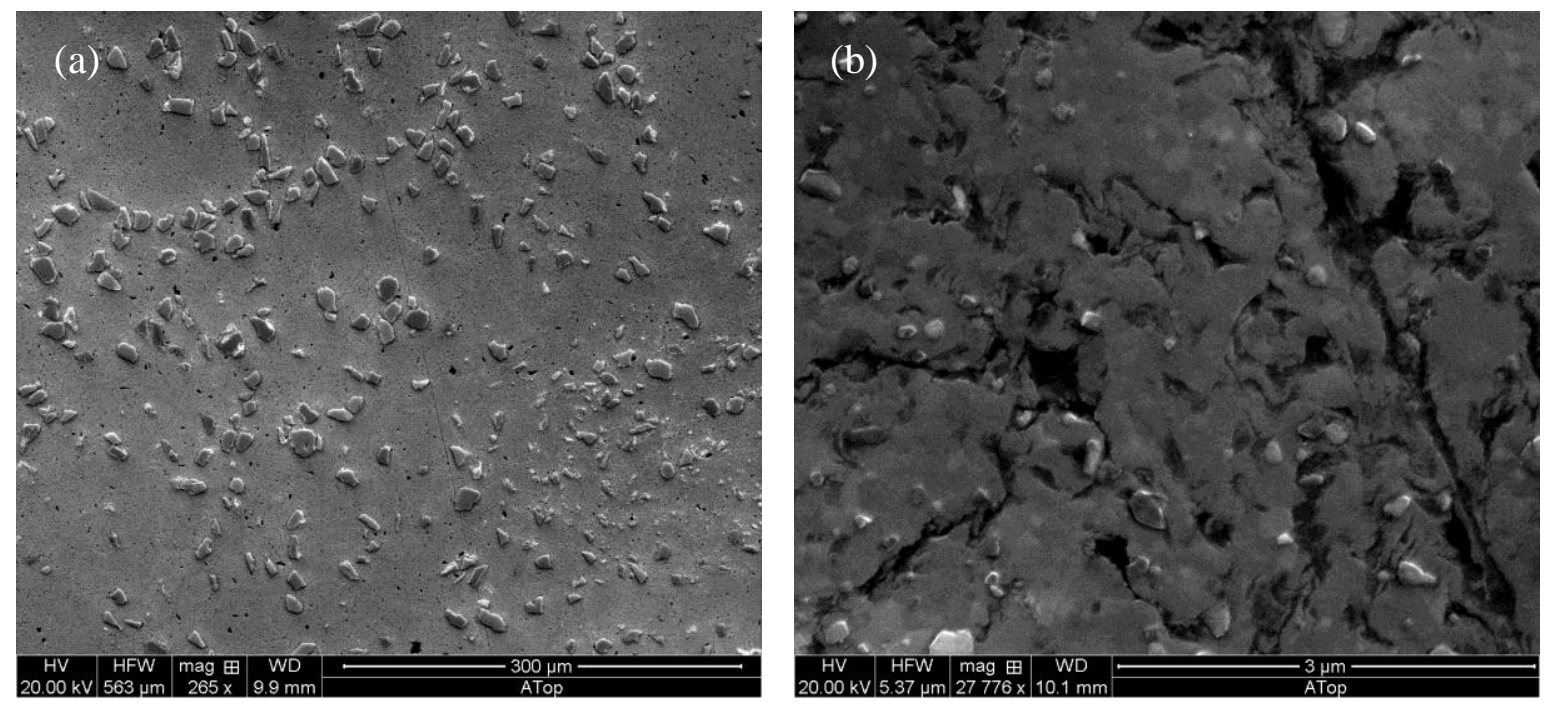

Fig. 1: SiC reinforced MMC processed by ex-situ technique with different particle sizes: (a) $13 \mu \mathrm{m}$ and (b) $0.7 \mu \mathrm{m}$.

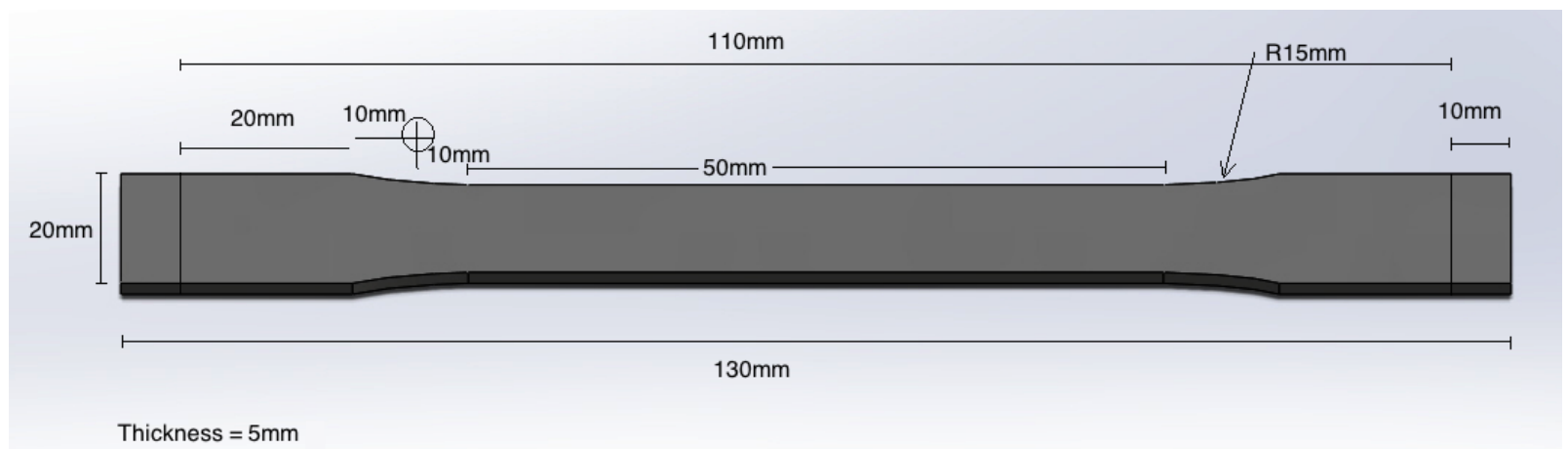

Fig. 2: Schematic of specimen for load-extension experiment drawn in SolidWorks.

Before carrying out the load-extension tests, the machined specimens were subject to roughness (Ra) measurements with the help of Mitutovo Surftest SJ-201P profilometer. Measurements were carried out manually, for each plate with the average being taken over 5 runs. Representative profile of such 
measurements is shown in Fig. 3 for $13 \mu \mathrm{m}$ particle reinforced MMC machined at $1500 \mathrm{rpm}$ and 200 $\mathrm{mm} / \mathrm{min}$ feed rate. Roughness data along with input variables during machining the specimens are listed in Table 1. It seems, in general MMCs reinforced with larger particles shows higher roughness (Ra) compared to the one reinforced with smaller particles, regardless of milling parameters. After load-extension experiments, all the fractured surfaces of the samples were investigated with the help of scanning electron microscope (MIRA, TESCAN) to unravel fracture mechanics.

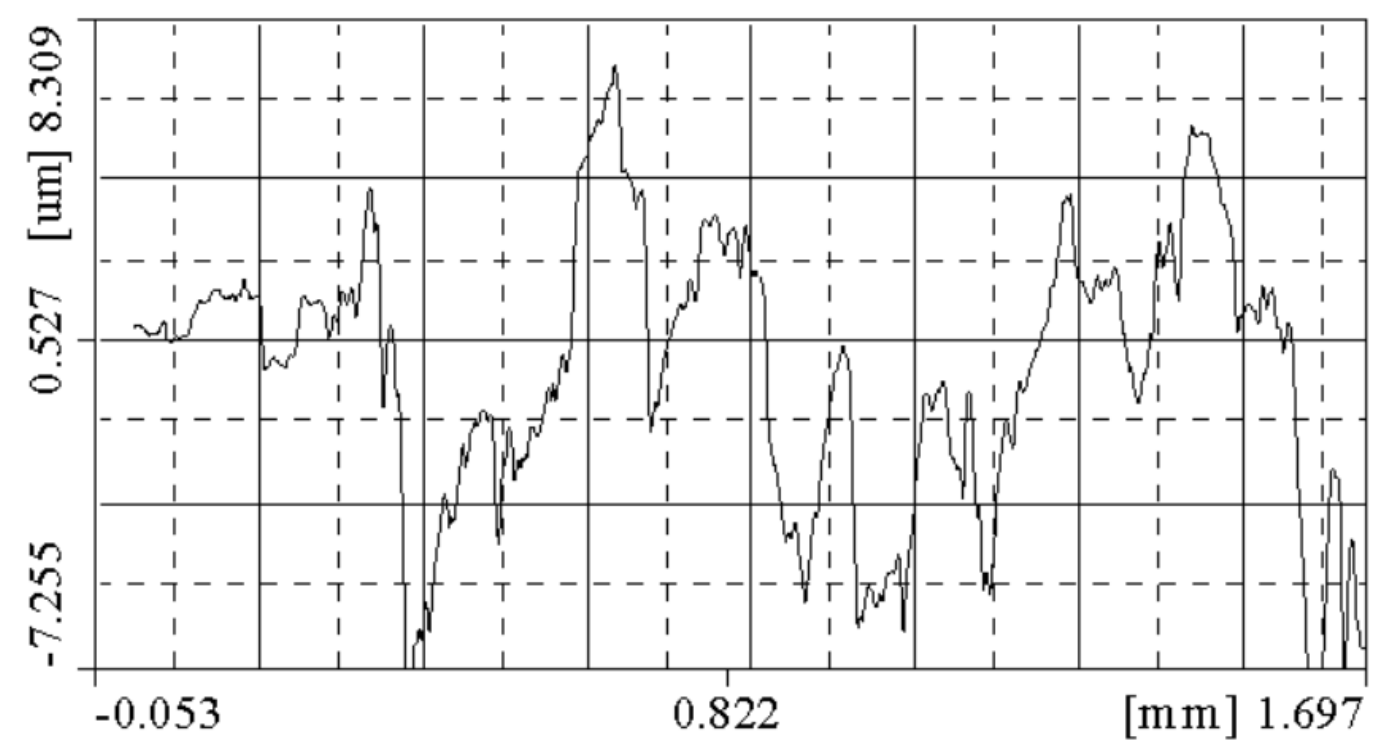

Fig. 3: Representative roughness $(\mathrm{Ra})$ profile of $13 \mu \mathrm{m}$ particle reinforced MMCs machined at 1500 $\mathrm{rpm}$ and $200 \mathrm{~mm} / \mathrm{min}$ feed rate

Table 1: Machining parameters used during milling of MMCs along with corresponding roughness (Ra) values of the machined parts.

\begin{tabular}{ccccc}
\hline Expt. no. & $\begin{array}{c}\text { Reinforced } \\
\text { particle Size } \\
(\boldsymbol{\mu m})\end{array}$ & $\begin{array}{c}\text { Spindle } \\
\text { speed } \\
(\mathbf{r p m})\end{array}$ & $\begin{array}{c}\text { Feed rate } \\
(\mathbf{m m} / \mathbf{m i n})\end{array}$ & $\begin{array}{c}\text { Surface } \\
\text { roughness, Ra } \\
(\boldsymbol{\mu m})\end{array}$ \\
\hline 1 & 13 & 1500 & 200 & 2.26 \\
2 & 0.7 & 1500 & 200 & 1.06 \\
3 & 13 & 2500 & 200 & 3.01 \\
4 & 0.7 & 2500 & 200 & 1.32 \\
5 & 13 & 1500 & 600 & 3.88 \\
6 & 13 & 2500 & 600 & 2.90 \\
7 & 0.7 & 1500 & 600 & 1.14 \\
8 & 0.7 & 2500 & 600 & 1.19 \\
\hline
\end{tabular}


In this investigation, materials and machining parameters have been categorised in 'low' and 'high' values. The 'low' values indicate the lower magnitude of parameters $(0.7 \mu \mathrm{m}$ particles, $1500 \mathrm{rpm}$ speed and $200 \mathrm{~mm} / \mathrm{min}$ feed rate) except the one under comparison. Similarly 'high' indicate the higher magnitude of parameters (13 $\mu \mathrm{m}$ particles, $2500 \mathrm{rpm}$ speed and $600 \mathrm{~mm} / \mathrm{min}$ feed rate) except the one under comparison. Interactions between different parameters have significant influence on the surface integrity pf the machined parts [15-17]. Therefore, in order to include this effect in our analysis different parameters at high and low values have been discussed and explained.

\section{Results and discussions}

Fig. 4 shows the effects of different parameters used during machining of MMC specimens on loadextension curve when the constant parameters are of low values. Curves 1 and 2 in Fig. 1 compare the influence of the reinforced particle size on load-extension curves. At this conditions (1500 rpm speed and $200 \mathrm{~mm} / \mathrm{min}$ feed rate), MMCs reinforced with larger particles showed higher strength. It requires higher load for similar extension of MMC reinforced with smaller particles. However, the total extension of MMC reinforced with smaller particles is higher at break indicating higher ductility which is line with experimental findings reported in literature $[1,18]$ which depends on the reinforcement content, heat treatment conditions and range of reinforcement sizes [11]. The effect of machining speed on load-extension curve can be observed by comparing curves 2 and 4 in Fig. 1. It also shows that the stiffness of the specimens doesn't depend on the speed at lower range of load, however, at higher range of loads, specimens machined at faster speed shows higher stiffness. The material with higher stiffness requires higher load to make similar extension. MMC machined at higher speed requires higher load and more extension than that of low speed. This is due to strain rate dominance at low cutting speed which probably causes inhomogeneous deformation resulting in more defects in the machined surface. On the other hand, increase of speed reduce thermal effects that may reduce the inhomogeneous deformation of material and increase the ductility of matrix which reduces the defects in the machined surface and increase the stiffness [4, 19] . Curves 2 and 7 in Fig. 4 compare the effect of feed rate on load-extension curve where all the other constant parameters, such as speed $(1500 \mathrm{rpm})$ and reinforcement size $(0.7 \mu \mathrm{m})$ were of low values. These show that the stiffness of the two parts machined at different feed rates is identical at lower load but at higher load, the part machined at higher feed rate shows higher stiffness compare to that at lower feed rate. The tool-particle interaction reduces at higher feed rate which reduces the damages in the 
machined surfaces [4]. In this case, the parts will have higher resistance to crack initiated deformation. Therefore, higher feed provides better stiffness on the machined MMC part.

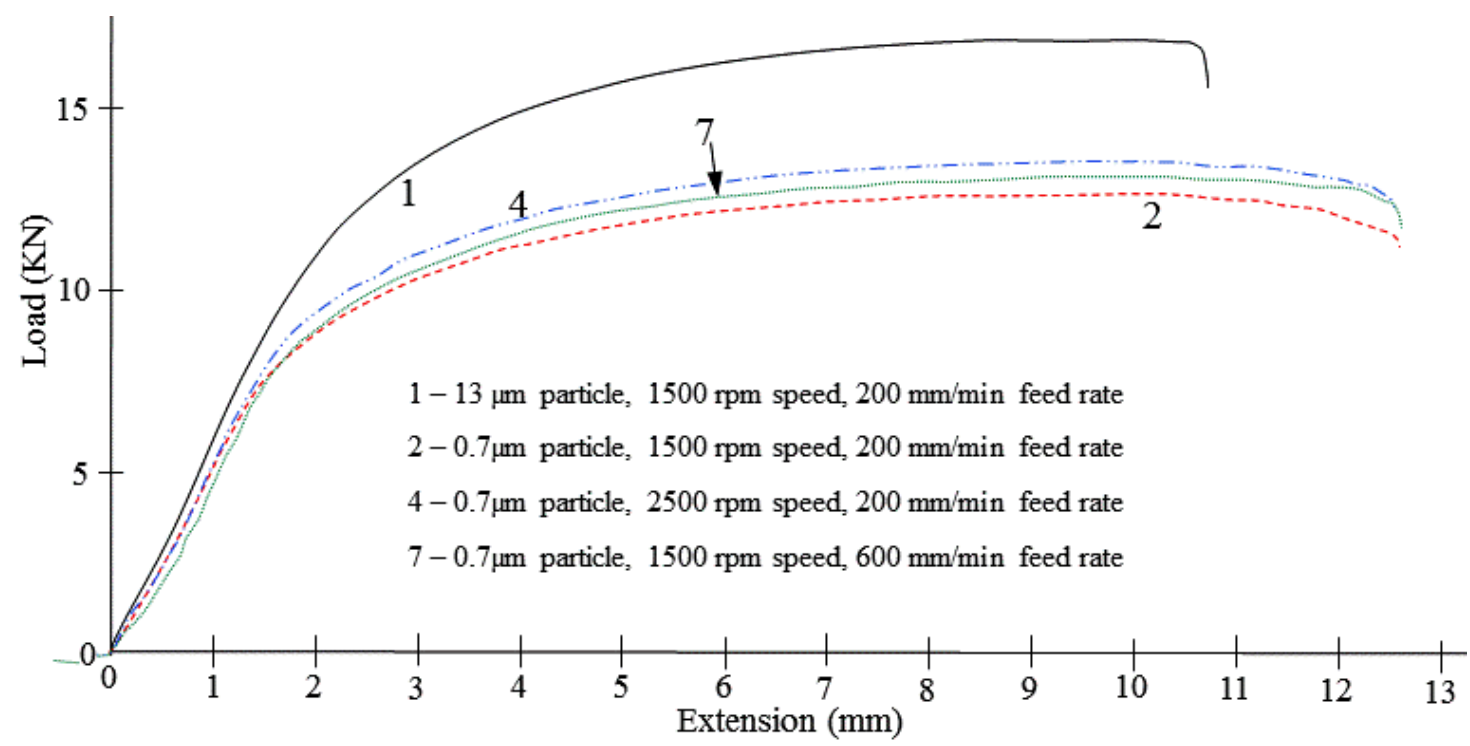

Fig. 4: Load- extension curves for different MMC specimens for comparison (at low values of constant parameters).

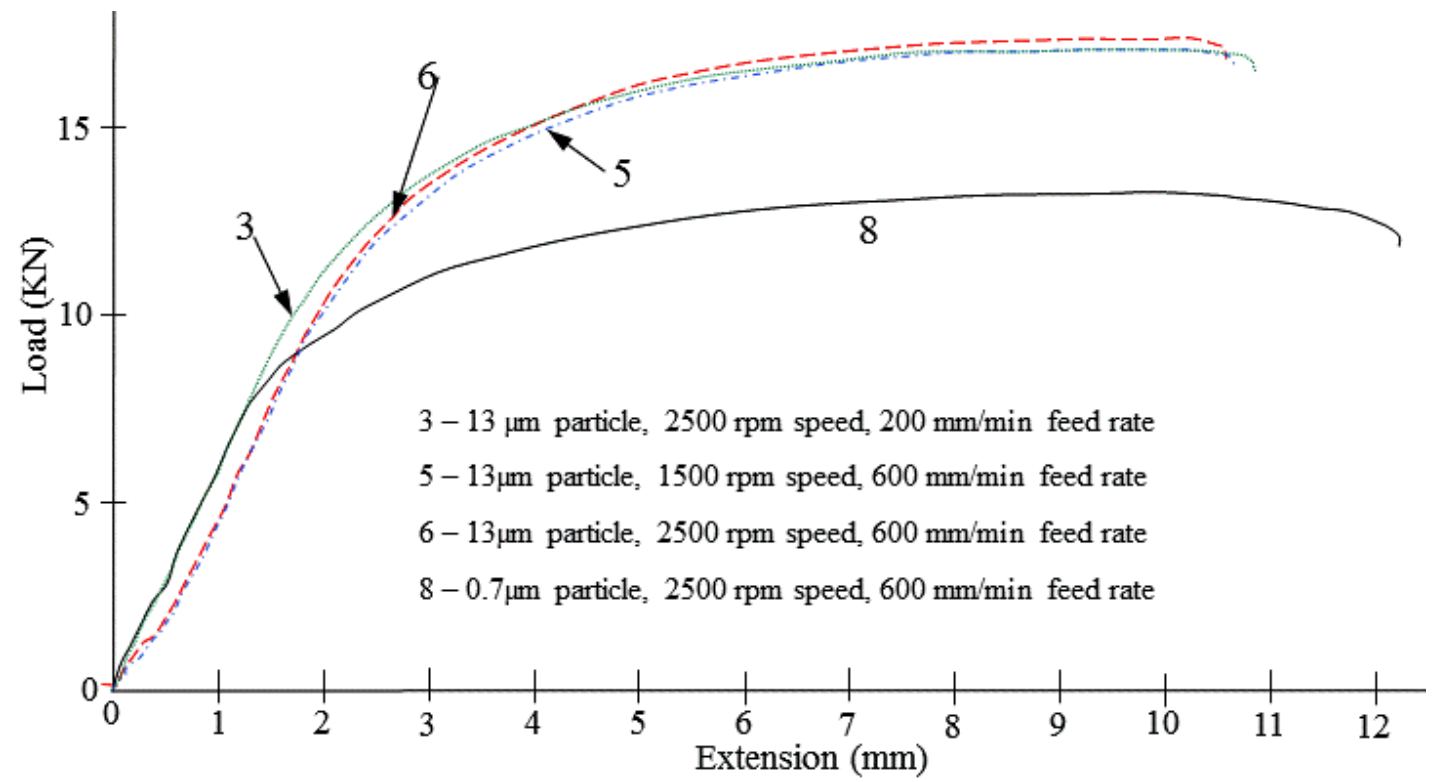

Fig. 5: Load- extension curves for different MMC specimens for comparison (at high values of constant parameters). 
Effects of different machining parameters on MMC specimens under load-extension experiments, when the constant parameters are of high values, are given in Fig. 5. It shows that the stiffness of the MMC reinforced with bigger particle (curve 6) shows higher stiffness than that of MMC reinforced with smaller particle (curve 8) at higher load. In this case the also, the parts machined at higher speed (curve 6) shows higher stiffness compare to that of lower speed (curve 5) at higher load. The effect of feed rate on the stiffness is not distinguishable at higher load when curves 3 and 6 are compared. However, parts machined at lower feed rate are stiffer than that at lower feed rate at lower load.

Figures 4 and 5 clearly show that the size of the reinforced particle is main contributing factor in the load-extension curves. The curves generated from parts machined at different conditions are very close to each other when the size of the reinforcements is constant. However, distinct entity of the curves for different machining conditions was clearly noted when the size of the particles is smaller as shown in Fig. 4. On the other hand, the curves for different machining conditions were completely overlapped to each other when the size of the particles is bigger as shown in Fig. 5.

The influence of particle size and machining parameters on the tensile strength for high values of constant parameters is shown in Fig. 6. It shows that larger reinforcements and speed give higher tensile strength compare to that of smaller reinforcement and speed. However, the effect of feed on the tensile strength is negligible for the range of machining conditions considered in this investigation. On the other hand, when the constant input parameters are of high values, the effect of reinforcement size on tensile strength is negligible as shown in Fig. 7. The higher speed and lower feed rate give higher tensile strength for the considered range of parameters.

The effect of reinforcement size and machining parameters on strain at break is given in Figures 8 and 9. The values of constant parameters are higher and lower in Figures 8 and 9 respectively. Fig. 8 shows that only the machining speed significantly affects the strain at break. Other factors, such as reinforcement size and feed rate have minor effect on strain at break. It shows that this strain is lower when the speed is higher for the considered range of parameters. However, all the factors affect the strain at break when the values of constant parameters are higher as shown in Fig. 9. It shows that smaller reinforcement, speed and feed give higher strain at break. 


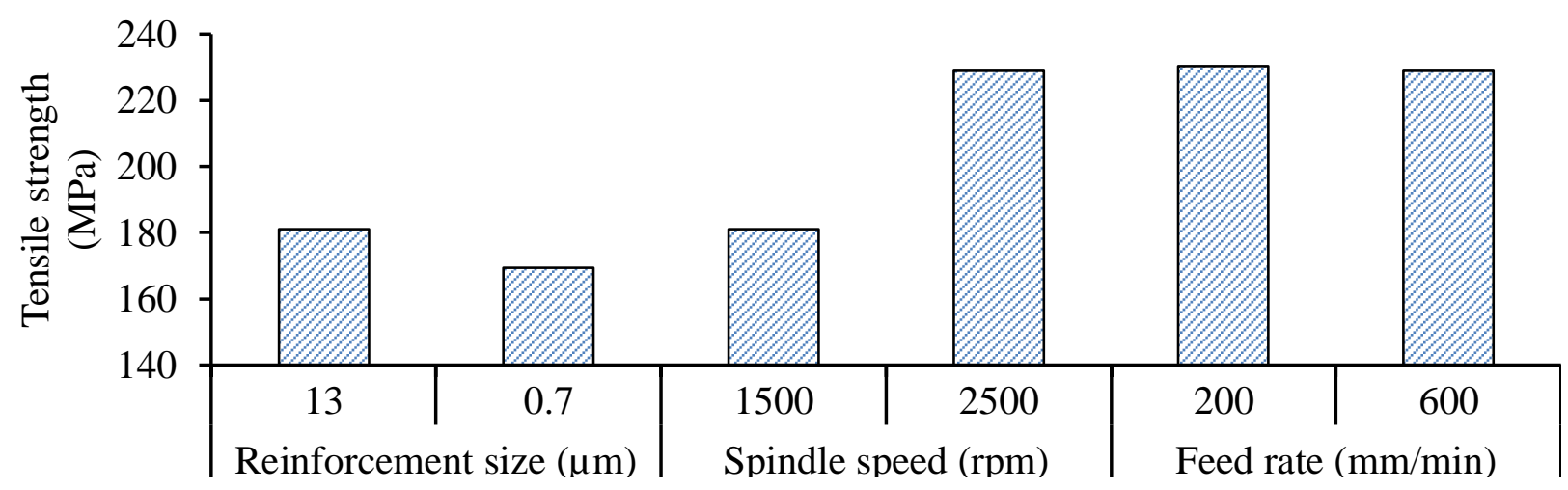

Fig. 6: Influence of different parameters on tensile strength at high values of constant parameters.

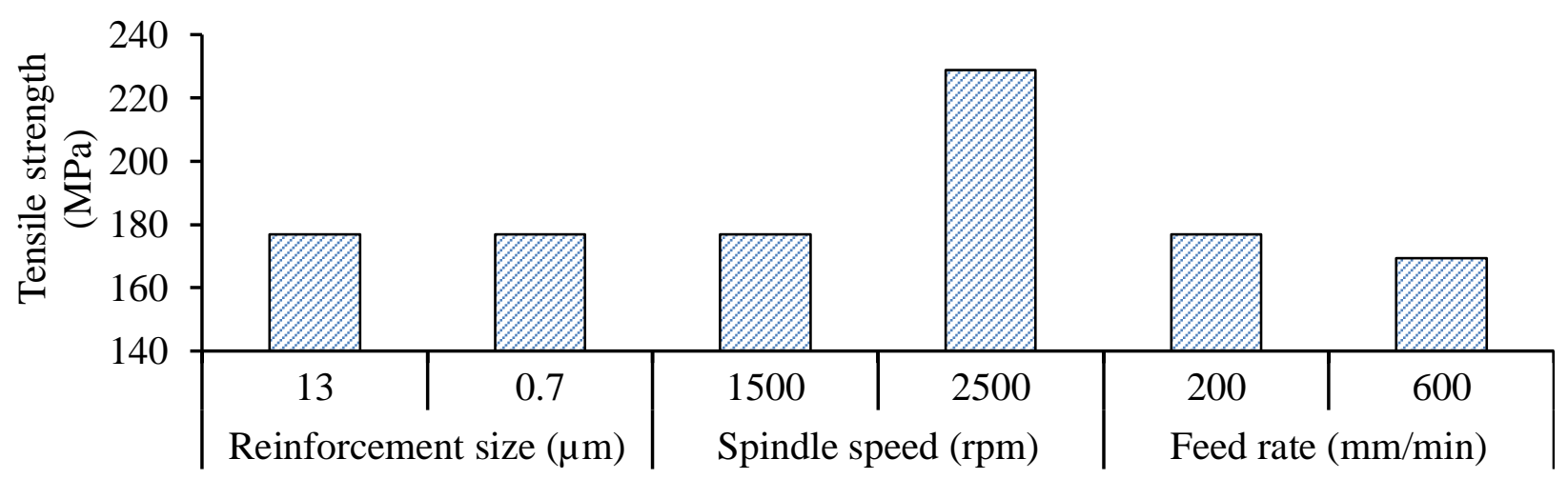

Fig. 7: Influence of different parameters on tensile strength at low values of constant parameters.

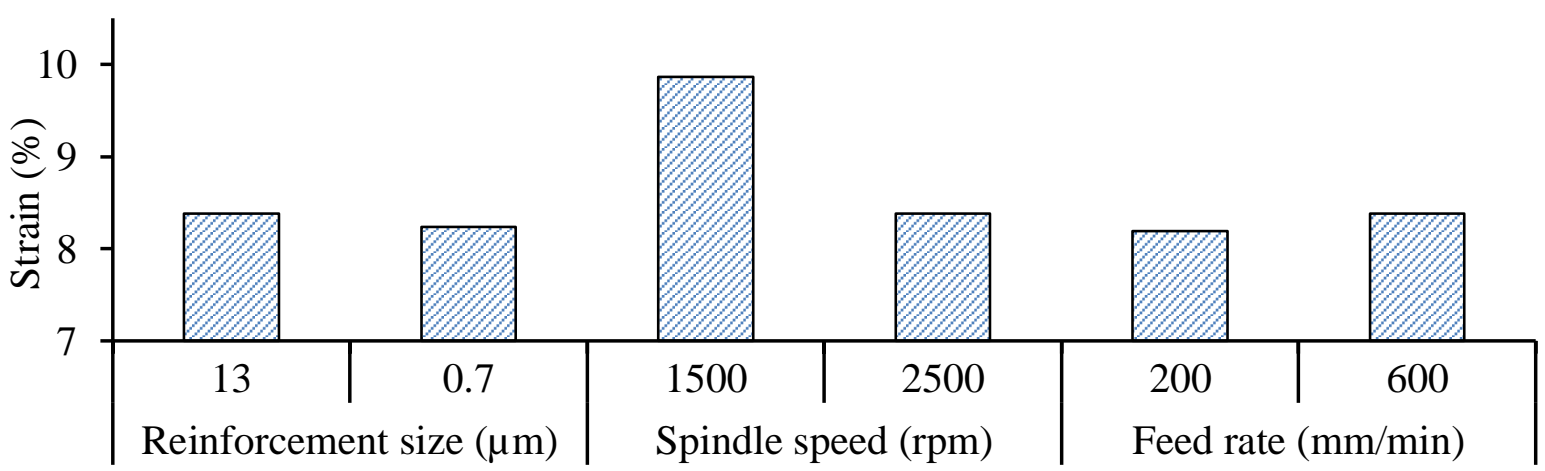

Fig. 8: Influence of different parameters on strain at high values of constant parameters. 


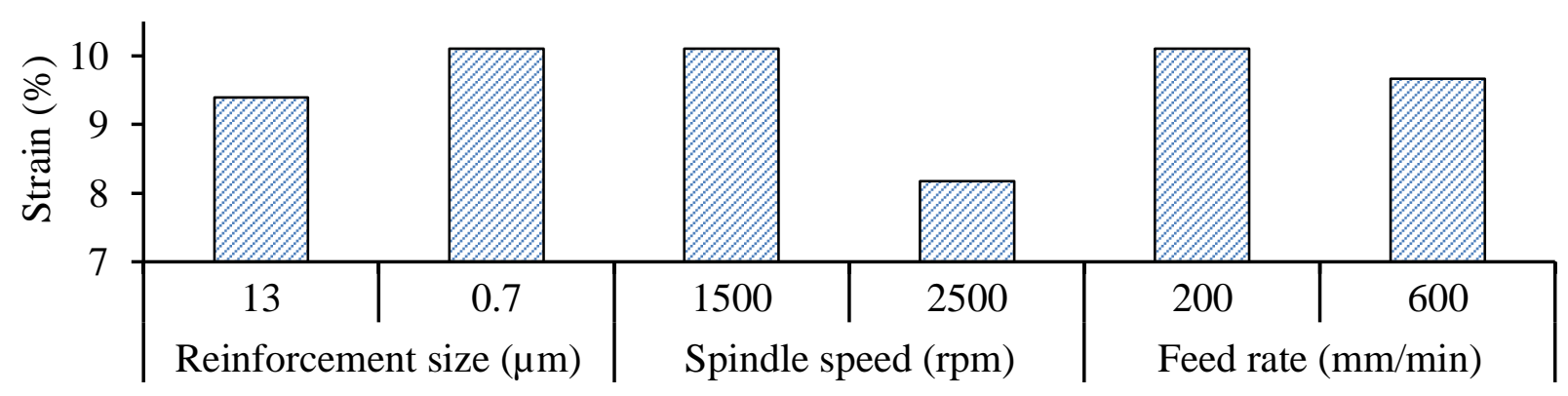

Fig. 9: Influence of different parameters on strain at low values of constant parameters.

The micrographs of the fractured surfaces are presented in Fig. 10 for samples machined with high values of constant parameters. It clearly shows the ductile nature of fracture in all cases due to the presence of cleavage fracture and dimples. The fractured and dislodged particles are clearly visible in most of the cases. It seems that machining conditions don't have mentionable effect on the fractured surface when the size of the reinforcements is constant. The dimples in the cleavage fracture become smaller when the particles are smaller in case of higher values of constant machining parameters. Fig. 11 presents the micrographs of the fractured surfaces for samples machined with high values of constant parameters.
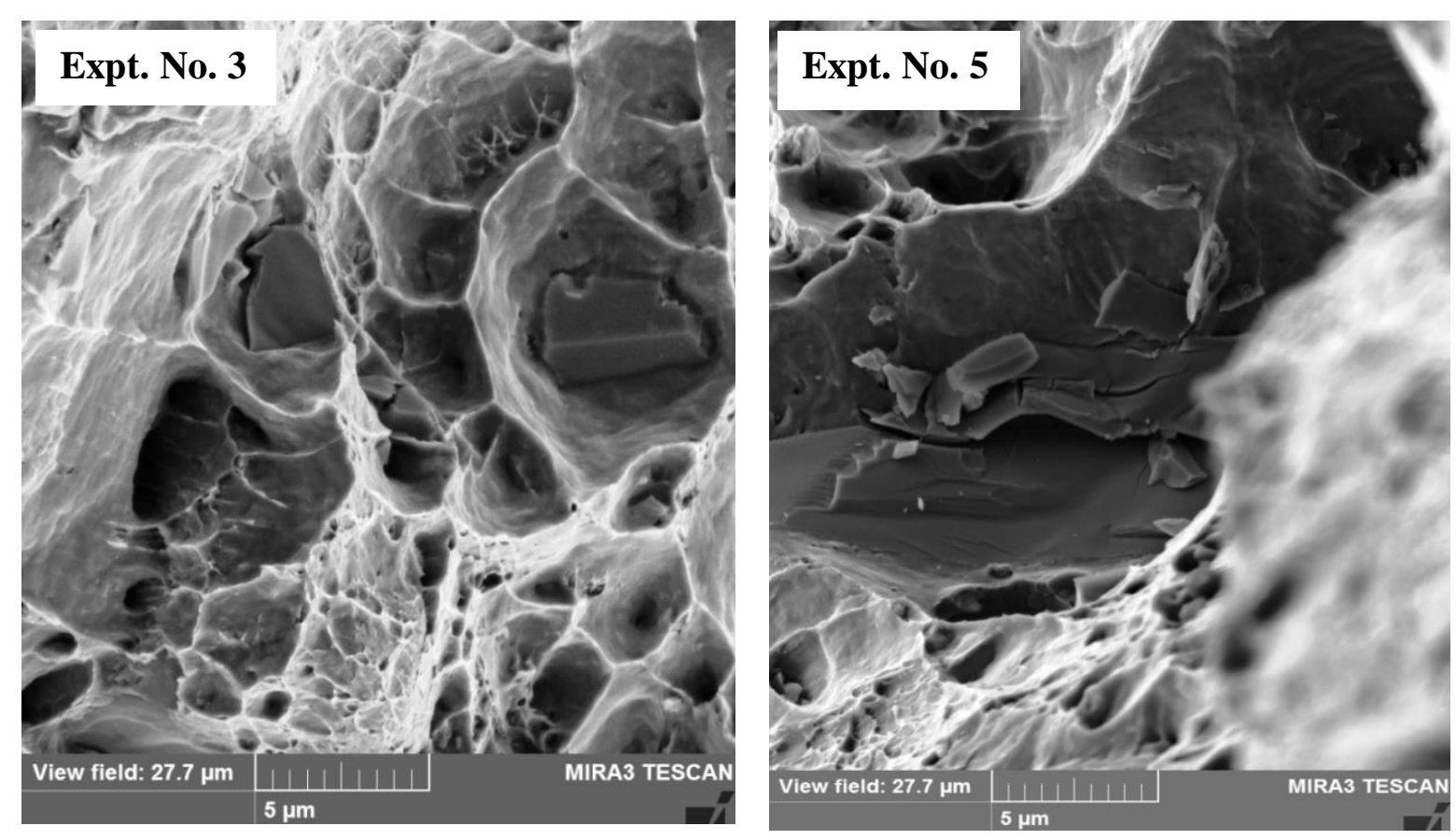

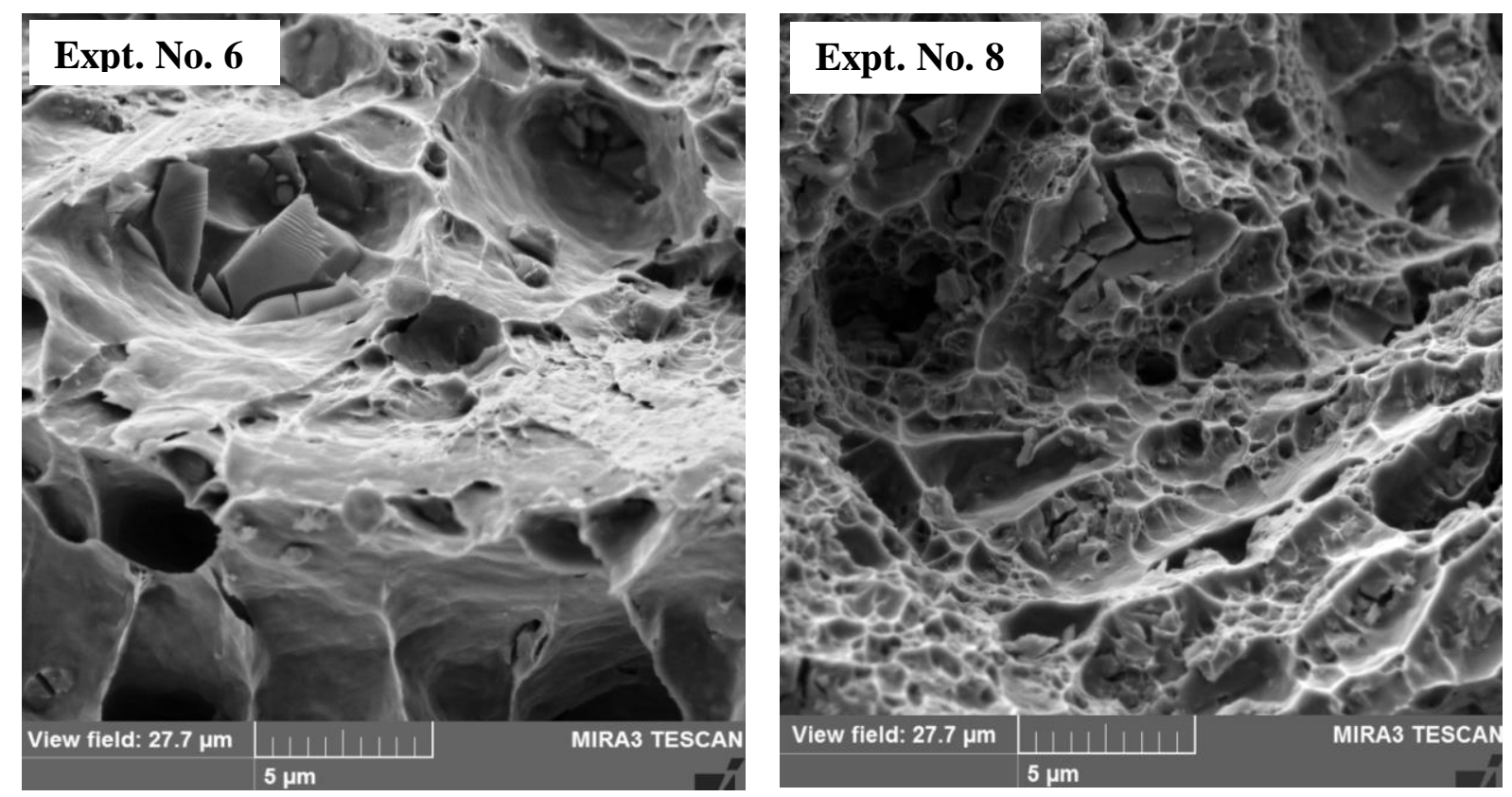

Fig. 10: SEM of fractured surfaces after load-extension experiments on different specimens fabricated according to the parameters shown in table 1 (at high values of constant parameters).
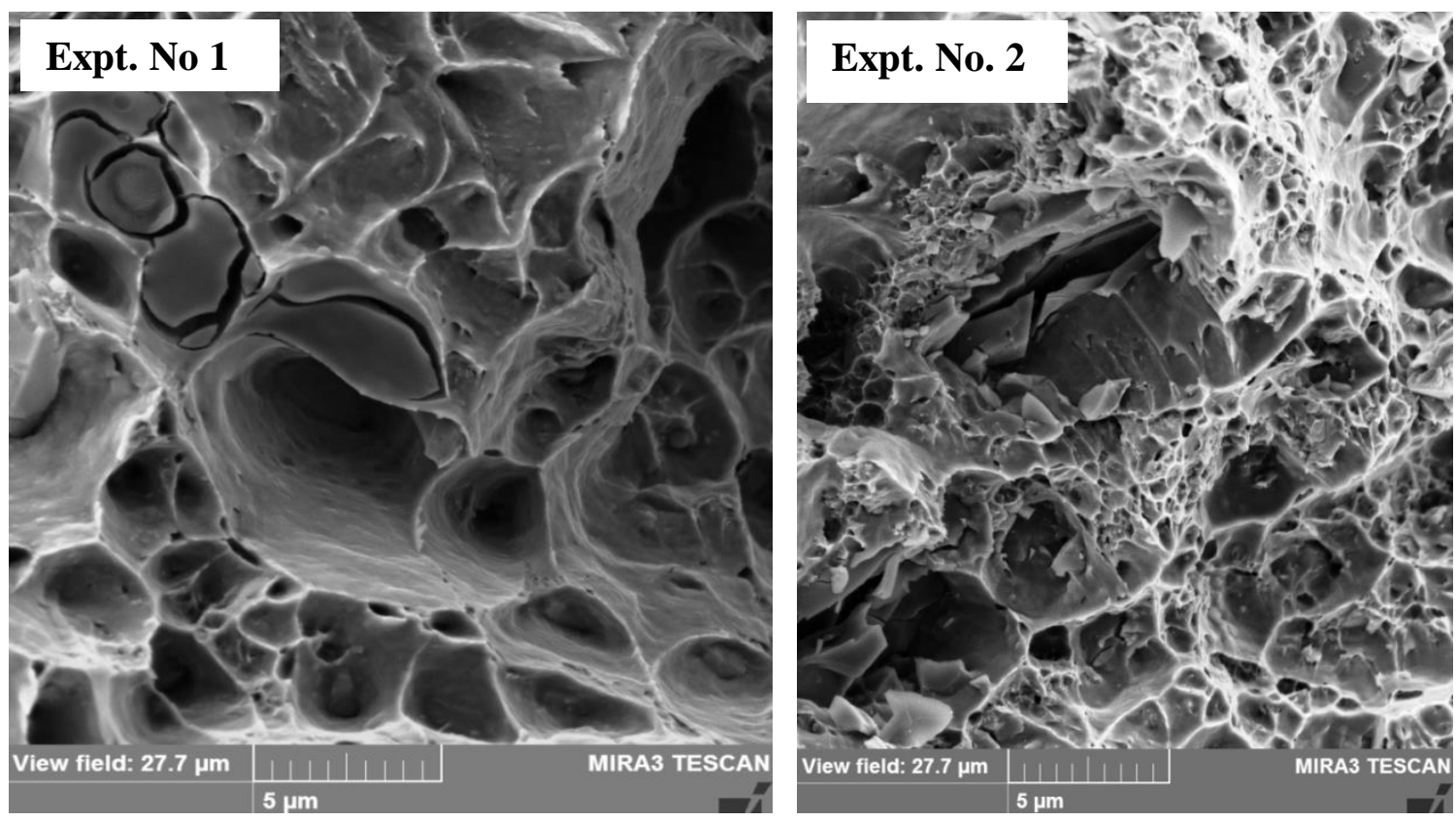

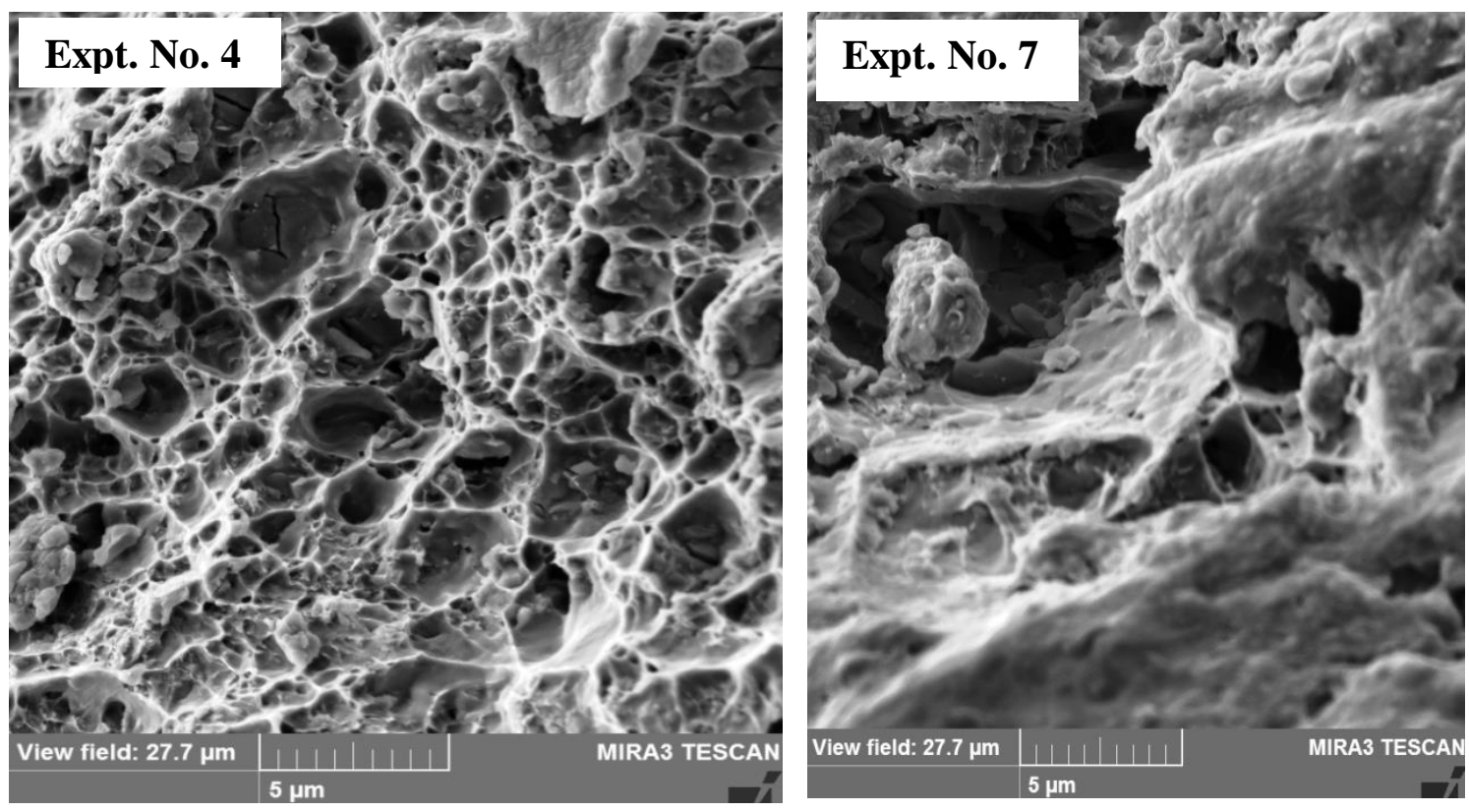

Fig. 11: SEM of fractured surfaces after load-extension experiments on different specimens fabricated according to the parameters shown in table 1, at low values of constant parameters

Similar to Fig. 10, ductile nature of fracture occur in all cases as well, as the cleavage fracture and dimples were noted. However, the finer dimples were present in all machining condition where size of the particles is smaller. The fractured and pulled out particles were not noted in this case but cleavage steps and ductile tearing ridges were clearly visible regardless of experiment conditions. The dimples of the cleavage fracture become bigger when the reinforced particles were bigger for the series of variables considered in this study.

\section{Conclusions}

After analysing the influence of reinforced size and machining parameter, such as speed and feed, their interactions on the on the deformation of Metal Matrix Composites (MMCs) under tensile load, the following conclusions can be made.

(a) Reinforcement size has much higher effect on the stiffness of the machined MMC components than that of machining parameters. Larger particles induce higher stiffness to MMC for experimental condition considered in this investigation. 
(b) Higher speed and feed induce higher stiffness on the machined MMC parts where constant input parameters are of low values. The influence of feed and speed on stiffness is not significant when constant input parameters are of low values.

(c) Larger reinforcements and speed give higher tensile strength and the effect of feed is negligible when constant input parameters are of high values. The effect of reinforcement size on tensile strength is negligible and, higher speed and lower feed rate give higher tensile strength when constant input parameters are of low values.

(d) The higher machining speed gives higher strain at break though reinforcement size and feed rate have minor effect on strain at break when the constant input parameters are of high values. When the constant input parameters are of high values, the smaller reinforcement, speed and feed give higher strain at break.

(e) Ductile fracture occurs to the specimen regardless of input variables. Only the size of the reinforcement affects the structure of the fractured surface by generating small dimples in the fractured surface for smaller reinforced particles. Fractured and pulled out particles were also noted on the fractured surface when the size of reinforced particles was bigger.

\section{References}

1. Basak, A., A. Pramanik, and M. Islam. Failure mechanisms of nanoparticle reinforced metal matrix composite. in Advanced Materials Research. 2013. Trans Tech Publ.

2. Pramanik, A., Developments in the non-traditional machining of particle reinforced metal matrix composites. International Journal of Machine Tools and Manufacture, 2014. 86: p. 4461.

3. Pramanik, A., Electrical Discharge Machining of MMCs Reinforced with Very Small Particles. Materials and Manufacturing Processes, 2015(just-accepted).

4. Pramanik, A., L. Zhang, and J. Arsecularatne, Machining of metal matrix composites: effect of ceramic particles on residual stress, surface roughness and chip formation. International Journal of Machine Tools and Manufacture, 2008. 48(15): p. 1613-1625.

5. Boswell, B., et al., Effect of machining parameters on the surface finish of a metal matrix composite under dry cutting conditions. Proceedings of the Institution of Mechanical Engineers, Part B: Journal of Engineering Manufacture, 2015: p. 0954405415583776.

6. Pramanik, A., J. Arsecularatne, and L. Zhang, Machining of particulate-reinforced metal matrix composites, in Machining. 2008, Springer. p. 127-166. 
7. Ramulu, M., G. Paul, and J. Patel, EDM surface effects on the fatigue strength of a 15 vol\% SiC p/Al metal matrix composite material. Composite structures, 2001. 54(1): p. 79-86.

8. Haque, S., P.K. Bharti, and A.H. Ansari, Mechanical and Machining Properties Analysis of Al6061-Cu-Reinforced SiC P Metal Matrix Composite. Journal of Minerals and Materials Characterization and Engineering, 2014. 2014.

9. Diler, E.A. and R. Ipek, An experimental and statistical study of interaction effects of matrix particle size, reinforcement particle size and volume fraction on the flexural strength of AlSiC p composites by P/M using central composite design. Materials Science and Engineering: A, 2012. 548: p. 43-55.

10. Qing, H., Micromechanical study of influence of interface strength on mechanical properties of metal matrix composites under uniaxial and biaxial tensile loadings. Computational Materials Science, 2014. 89: p. 102-113.

11. Doel, T. and P. Bowen, Tensile properties of particulate-reinforced metal matrix composites. Composites Part A: Applied Science and Manufacturing, 1996. 27(8): p. 655-665.

12. Sajjadi, S.A., H. Ezatpour, and M.T. Parizi, Comparison of microstructure and mechanical properties of A356 aluminum alloy/Al 2 O 3 composites fabricated by stir and compo-casting processes. Materials \& Design, 2012. 34: p. 106-111.

13. Pramanik, A., A. Basak, and M. Islam, Effect of reinforced particle size on wire EDM of MMCs. International Journal of Machining and Machinability of Materials, 2015. 17(2): p. 139-149.

14. Testing, A.S.f. and Materials. ASTM designation E 8-00 Standard Test Methods for Tension Testing of Metallic Materials. 2000. ASTM.

15. Islam, M., B. Boswell, and A. Pramanik. An Investigation of Dimensional Accuracy of Parts Produced by Three-Dimensional Printing. in Proceedings of the World Congress on Engineering. 2013.

16. Islam, M., et al., Effect of cooling methods on dimensional accuracy and surface finish of a turned titanium part. The International Journal of Advanced Manufacturing Technology, 2013. 69(9-12): p. 2711-2722.

17. Islam, M. and A. Pramanik, Effects of Insert Geometry and Feed Rate on Quality Characteristics of Turned Parts. Journal of Advanced Manufacturing Systems, 2015. 14(03): p. 149-166.

18. Pramanik, A. and G. Littlefair. Fabrication of nano-particle reinforced metal matrix composites. in Advanced Materials Research. 2013. Trans Tech Publ.

19. El-Gallab, M. and M. Sklad, Machining of Al/SiC particulate metal matrix composites: Part II: Workpiece surface integrity. Journal of Materials Processing Technology, 1998. 83(1): p. 277-285. 